\title{
Social Media Adoption Intention among Undergraduate Business Schools Students in Kathmandu Valley: A Structural Equation Modeling (SEM) Approach
}

\author{
Laxman Pokhrel
}

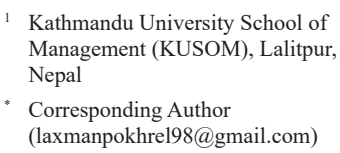

Kathmandu University School of Management (KUSOM), Lalitpur, Nepal

* Corresponding Author (laxmanpokhre198@gmail.com)

Received: 09 May, 2021

Revised: 31 August, 2021

Accepted: 10 November, 2021

Published: 25 December, 2021

How to cite this paper:

Pokhrel, L. (2021). Social media adoption intention among undergraduate business schools students in Kathmandu valley: A structural equation modeling (SEM) approach. Quest Journal of Management and Social Sciences, 3(2), pp. 204-216.

Copyright (C) 2021 by authors and Quest Journal of Management and Social Sciences.

This work is licensed under a Creative Commons Attribution-Non Commercial-No Derivatives 4.0 International License.

https://creativecommons.org/ licenses/by-nc-nd/4.0/

\section{Abstract}

Background: Social Media has become a prevalent platform for students to receive information content such as admission notices, holiday notices from business schools. Students are communicating, collaborating, and resource sharing by several social media in the names of support groups.

Objective: The purpose of the research paper is to examine social media adoption intention among undergraduate students of business schools in Kathmandu Valley in 2020.

Method: The data were collected with the self-administered questionnaires from 200 undergraduate students. Partial Least Square (PLS) - SEM was applied to test the direct and mediated effect of the proposed hypotheses.

Result: The results revealed that perceived ease of use, perceived usefulness, collaboration, resource sharing, communication and intention of social media adoption. Perceived ease of use partially mediates the relationship between communications, resource sharing on the intention of social media adoption.

Conclusion: The study concludes that undergraduate level students of business schools could intent to social media when they find the social media useful, easy to use, collaborative, communication, and resource sharing among students. Moreover, students could intend to use social media when they perceived ease of social media use over communication, resource sharing for educational purposes. The conclusion could provide information for business schools in creating an atmosphere of collaboration, communication, and resource sharing to increase engagement in social media.

Originality: Social media adoption in the Nepali context is a relatively less explored phenomenon. This research established that social media adoption is impacted by collaborative learning, resource sharing, perceived usefulness, and communication.

Paper Types: Research Paper

Key Words: Structural equation modeling, perceived ease of use, perceived usefulness, communication, collaboration, resource sharing

JEL Classification: M3 


\section{Introduction}

The extraordinary growth of interactive social media has impacted almost every aspect of daily lives over the past decades. Out of 7.77 billion people in the world, 4.54 billion are active internet users in which the largest percentage of internet users $50.3 \%$ are from the Asian continent (Internet Live Stats, 2020). There are about 3.8 billion active social media users in which there are more than 2 billion Facebook users, more than 350 million Twitter users, more than 550 million Google+ users, and more than 400 million LinkedIn users (Internet Live Stats, 2020). With the exponential growth of social media users, social media platforms are not only a significant part of users' everyday lives but also communication tools for organizations. Arshad and Akram (2018) states that social media platforms were initially created with the purpose of interaction and communication. Because of ease of use and usefulness for collaboration and communication, the academic community has captured the advantages of social media usages over traditional communication tools (Berger, 2017; Forbes, 2017; Tess, 2013).

While the debate continues regarding the pros (socialization, engagement of students, development of a community, collaborative and reflective learning, peer-to-peer support and feedback, employment resource, and information management) and cons (cyberbullying, ownership issues, workload issues, lack of student engagement, lack of trust in peer feedback, and technology infrastructure issues) of using social media for academic practice, no one can argue the influence that social networking has on today's students (Lederer, 2012; Lester \& Perini, 2010). As the demand for higher education grows and the competition for the best students intensifies, colleges and universities find themselves searching for ways to recruit students. Students have shown a distinct preference for reaching out to their prospective schools via social media (Hayes et al., 2009) thus making use of a rich social media presence a necessary tool in today's higher education marketing environment (Sandvig, 2016). Likewise, the engagement in the higher education sector can be an attractive proposition for the adoption of social media (Boyd, 2008).

Social media adoption has been studied applying several theoretical grounds such as the theory of planned behavior, innovation diffusion theory, and technology acceptance model, the unified theory of acceptance and use of technology. Regardless of the availability of technological based theories and models, the technology acceptance model (TAM) has been the most widely applied model on a global scale (Al-Ghaith, 2015). This model has two dimensions perceived usefulness (PU) and Perceived Ease of Use (PEU). The PU refers to the degree to which a person believes that using a particular system would enhance his or her job performance (Davis, 1989). The PEU refers to the degree to which a person believes that using a particular system would be free of effort (Davis, 1989). Several previous studies applied this framework to study social media adoption including other variables in the literature (Yadegaridehkordi et al., 2019). Moreover, Arshad and Akram (2018) investigated the intention of social media adoption with collaborative learning, resource sharing, and communication variables. The theoretical base for the study is the constructive theory of Vygotsky (1978). The constructivist theory states that learners rely on one another to accomplish tasks they otherwise would not complete individually. Therefore, it is logical to incorporate other variables in the existing model of TAM such as communication, collaboration, and resource sharing. Thus, the purpose of the paper was to investigate the intention of social media adoption by undergraduate students of business schools in Kathmandu Valley.The paper has three folds implications. First, this paper could provide insights to the social media adoption across cultures in business schools. Second, this paper examines the mediating role of communication, collaboration, and resource sharing about perceived usefulness and perceived ease of use. Finally, this study integrates the Technology Acceptance Model (TAM) and Constructivist theory for explaining the mediating effects on social media adoption.

This paper is composed of five different sections. The next section deals with a literature review of several constructs and their relationship among constructs. The following section deals with the research method in which describes the research design, sample, reliability, and validity. The second 
last section deals with testing hypotheses. The final section deals with the discussion, conclusion, and implications of the research.

\section{Review of Literature and Conceptual Framework}

Social media refers to several web-based platforms developed for individuals and communities to share information and opinions to co-create content (Kietzmann et al., 2011). The paper is based on intention of social media adoption in undergraduate business schools. This study applied that TAM as the conceptual framework for study social media adoption (Davis, 1989). Despite the variations of theories, TAM has been extensively used in several types of research due to its simplicity, adaptability, and parsimoniousness (Marangunić \& Granić 2015; Rauniar et al. 2014). Moreover, Boonsiritomachai and Pitchayadejanant (2017) state that TAM has explained information technology adoption within various cultures, contexts and organizations. The TAM explains a significant portion of the variance of social media adoption. It has the following two major dimensions;

Perceived Usefulness (PU): It is the perception of users of social media that interprets the application of social media to increase their performance. Consistent with the literature, TAM has been found helpful in evaluating and forecasting the use of technology in academia (Lu, Yao, \& Yu, 2005). Likewise, Dumpit and Fernandez (2017) found that on social media in higher education institutions, they emphasized that PU influences attitudes and which in turn leads to behavioral intention to use social media. In the Nepali banking context, Pokhrel, Adhikari, and Mishra (2020) found a significant positive effect of perceived usefulness on behavior intention of mobile banking adoption. Based on the empirical findings and conceptual background, the paper hypothesizes that;

\section{Hypothesis 1: Perceived usefulness positively influences Intention of social media adoption.}

Perceived Ease of Use (PEU): It refers to the degree to which a student believes that social media will be easy to use and free of effort to use. Social media is likely to adopt by the users if it has functional comfort. The study of Lu et al. (2005) found that PE is the eminent behavioral belief as an antecedent of the intention of technological acceptance. Davis (1989) found a significant influence of PEU on PU. Likewise, Pokhrel et al. (2020) PEU has a significant influence on PU in Nepali Context. PEU and PU have a positive effect on users' social media attitudes, however, there is no strong evidence which one of them explains users' attitude toward social media in the academic community (Lowry, 2002). Due to the unpredicted nature of the relationship, the paper has formulated the following hypotheses;

\section{Hypothesis 2a: Perceived ease of use positively influences social media adoption Intention.}

Hypothesis 2b: Perceived ease of use positively influences perceived usefulness of social media.

\section{Resource Sharing}

Resource or material sharing refers to academics' positive attitude sharing educational material with colleagues or students through social media platforms which allow disseminating user-generated content and resources (Kaplan \& Haenlein, 2010). Social media helps to promote online learning resources by providing collaborative platforms by sharing resources (Forkosh-Baruch \& Hershkovitz, 2012). Arshad and Akram (2018) found a significant influence of PU and PEU on resource sharing. Thus, researcher sharing can lead to the intention of social media adoption. Based on the findings and reviews, the researcher hypothesized;

Hypothesis 5a: Perceived usefulness mediates the relationship between resource sharing and intention of social media adoption.

Hypothesis 5b: Perceived ease of use mediates the relationship between resource sharing and intention of social media adoption. 


\section{Conceptual Framework}

The paper applied the conceptual framework developed by Arshad and Akram (2018) in the Pakistani context. Since the cultural background of Pakistan is different from that of Nepal, and Arshad and Akram (2018) recommended researching the different countries and contexts, the paper adopted a framework for the intention of social media adoption among undergraduate students of business schools. Likewise, Pandey and Yadama (1992) stated that cultural compatibility and relative advantage are crucial for the adoption of new technology. Thus, it is rationale to investigate the framework among undergraduate business students of Nepal.

Figure 1. Conceptual Framework

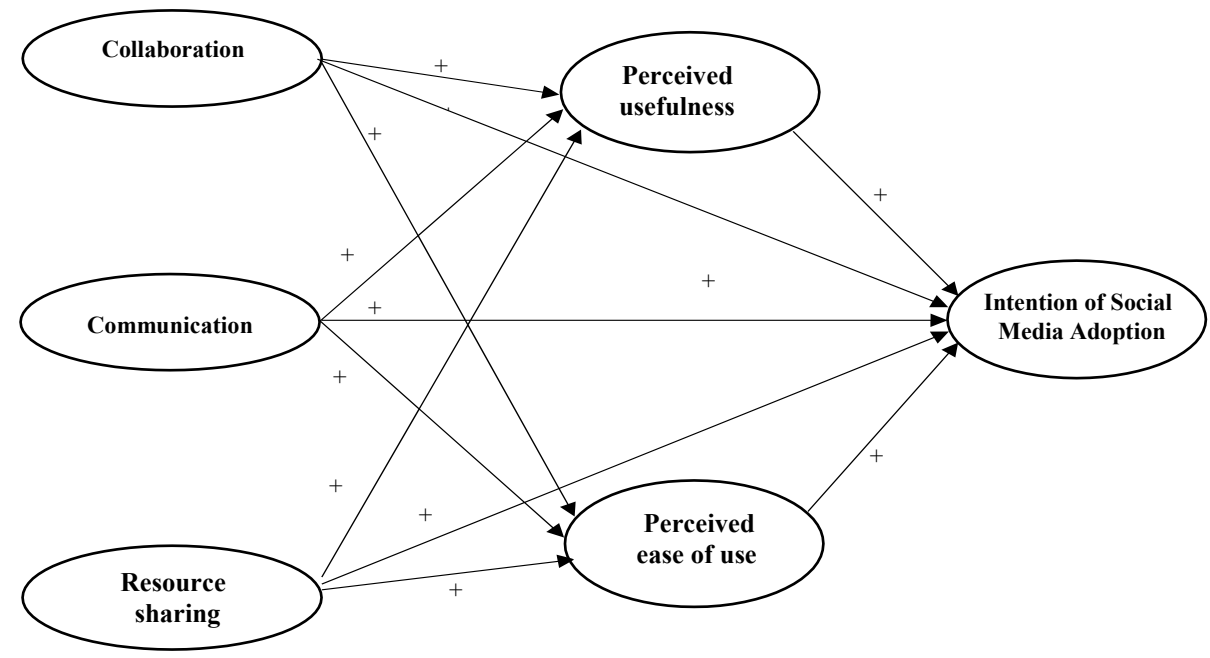

Source: Arshad \& Akram (2018)

\section{Research Methods}

\section{Sample and Data Collection}

The study applied the cross-sectional survey design. The population of the study comprised undergraduate students from different universities located in Kathmandu Valley. There are five universities Tribhuvan, Kathmandu, Pokhara, Purbanchal, and Foreign University which are offering a BBA degree. The researcher applied purposive sampling (Non-random sampling) because of the accessibility of students, location of colleges, and time framework to complete the research work. Hair et al. (2016) argue that the sample size should be five-time greater (minimum) or ten greater than the items that are used to perform advanced multivariate tools such as the structural equation model. In this research, there are 24 items to capture the response of seven variables. The sample size could be range from 120 to 240 based on the recommendation of Hair et al. (2016). Thus, a sample size of 200 was more than the required sample size. The researcher approached different representative business schools and was required to fill the questionnaire for research purposes. One college from each university was selected based on the purpose of the study and about 50 questionnaires were filled by the respondents from each college of stated universities. To achieve stated the research objective, the unit of analysis applied individual students of the different universities of Kathmandu Valley.

Before the administration of the questionnaire, a pilot test was carried out with 38 research students of Rajdhani Model College. Apart from filling the questionnaire of 30 items, respondents were requested to provide feedback on the completion of time and the ease of understanding the items in the scale. 
Ideally, Cronbach's alpha coefficient of a scale should be above 0.60 (Pallant, 2020). Since all the items were found above the threshold level of 0.60 so the researcher has used the questionnaire for the final research.

Self-administered structured questionnaires were distributed with 350 students to different representative Business Schools from major universities through faculty and coordinators of five respective colleges. Out of 238 returned questionnaires, the researcher performed data cleaning. During the process of data cleaning, the data cleaning was performed by correcting missing data, unengaged responses, and wrong entries. The final 200 responses were used for further data analysis. The study utilized Smart PLS 2.0 and SPSS 25 for data analysis. The multi-collinearity assumption was tested before testing direct and mediated hypotheses.

\section{Measurements}

The social media adoption intention was measured by six latent constructs using a 5 Likert Scale. Respondents were asked to answer using a scale from 1 to 5 with $(1=$ "strongly agree", $5=$ "strongly disagree") higher scores representing lower the intention of social media adoption. It was measured by the six dimensions with 24 items. Perceived Usefulness (PU) was adopted from Davis (1989), and Venkatesh and Davis (2000). The sample item includes: "I find social media useful in my studies/ research." It comprises 4 items. Perceived Ease of Use (PE) was adapted from Davis (1989), and Venkatesh and Davis (2000). The sample item includes: "My interaction with social media is clear and understandable." It comprises 4 items. Communication was adapted from Ozkan and Koseler (2009). The sample item includes: "Social media makes communication easier with instructor/colleagues and other classmates for me." It comprises 4 items. Collaborative learning was adapted from So and Brush (2008). The sample item includes: "I actively exchange my ideas with group members." It comprises 4 items. Resource sharing was adapted from Bock et al. (2005). The sample item includes: "Sharing of my knowledge with other members of social media is always good." It comprises 4 items. Intention of Social media adoption was adapted from Bock et al. (2005). The sample item includes: "I intend to adopt social media for knowledge sharing." It comprises 4 items. The detailed instrument has been attached in the appendix section.

\section{Data Analysis and Result}

\section{Demographic Profile of the Respondents}

A total of 200 respondents participated in the research and they were using social media. The demographic characteristics are included gender, age, time spent on social media. Table 1 presents the details of the respondents' profiles.

Table 1: Demographics profile

\begin{tabular}{lcc}
\hline Characteristics & Frequency & Percentage \\
\hline Gender & 76 & 38.0 \\
Male & 124 & 62.0 \\
Female & & \\
Age( in Years) & 184 & 18.7 \\
Below 18 & 186 & 57.1 \\
18- 25 & & \\
Time Spent on SM(Daily) & 10 & 5.0 \\
Less than 1 hour & 56 & 28.0 \\
1-2 hours & 134 & 67.0 \\
Over 2 hours & &
\end{tabular}


The majority of the respondents in the research were Female $(n=124,62.0 \%)$. The majority of the respondent of the Age was 18-25 years $(\mathrm{n}=186,57.1 \%)$. Finally, the most frequently reported Time pend on social media was over 2 hours years $(n=134,67.0 \%)$.

Structural Equation Model (SEM): Data analysis was performed applying Partial Least Squares Structural Equation Modeling (PLS-SEM) with Smart PLS 2.2 (Ringle, Wende \& Becker, 2015). SEM is a flexible and powerful extension of the general linear model and can estimate the relationship between endogenous, exogenous, and mediating variables at the same time. CB-SEM is a preferred method when the goal is theory testing, theory confirmation, or the comparison of alternative theories (Hair et al., 2016). The main purpose of CB-SEM is to assess the fit between the theoretical covariance matrix and the covariance matrix of the context under study. However, PLS-SEM can be applied for exploratory research when the theory is less developed (Hair et al., 2016). The primary focus of the research is to predict and explain the key target construct and/or identify the key driver constructs (Hair et al., 2016). Moreover, since the paper examined the role technology acceptance model with different three constructs (collaboration, combination, and resource sharing), the relationship is in the initial stage of testing. Thus, PLS-SEM is a better method in this study.

Measurement Model (Reliability and Validity): Reliability and validity ensure the quality of measurement. To establish an outer model's reliability and validity, the paper applied three major criteria used as reliability analysis, convergent validity, and discriminant validity suggested by (Ringle et al., 2015).

Reliability analysis: Reliability is the consistency of responses. Composite reliability and Cronbach's alpha were measured by reliability. In Table 2, the Cronbach's alpha coefficient of a scale is greater than 0.60 (Pallant, 2020). Moreover, the composite reliability (CR) of the constructs is greater than 0.7 (Nunnally \& Bernstein, 1994). Therefore, the result confirms the reliability of the outer model.

Convergent validity: Convergent validity is described by Hair et al. (2016) as the levels of validity that are achieved as a result of the collective convergence of items of a similar group. It is measured by factor loadings, average variance extracted of various constructs. In Table 2, all the factor loadings are greater than 0.7 and AVE is greater than 0.50. This result confirms the convergent of the outer model.

Table 2: Constructs and measurement model

\begin{tabular}{|c|c|c|c|c|c|c|}
\hline Construct & Indicators & $\begin{array}{l}\text { Outer } \\
\text { loading }\end{array}$ & $\begin{array}{l}\text { Indicator } \\
\text { Reliability }\end{array}$ & $\begin{array}{c}\text { Cronbach's } \\
\text { Alpha }\end{array}$ & $\begin{array}{l}\text { Composite } \\
\text { Reliability }\end{array}$ & $\begin{array}{c}\text { Average } \\
\text { Variance } \\
\text { Extracted } \\
\text { (AVE) }\end{array}$ \\
\hline Perceived & PU 1 & 0.84 & 0.71 & 0.75 & 0.92 & 0.55 \\
\hline \multirow[t]{3}{*}{ Usefulness } & PU 2 & 0.70 & 0.49 & & & \\
\hline & PU 3 & 0.69 & 0.48 & & & \\
\hline & PU 4 & 0.72 & 0.52 & & & \\
\hline Perceived & PE 1 & 0.73 & 0.53 & 0.84 & 0.89 & 0.68 \\
\hline \multirow[t]{3}{*}{ Ease of Use } & PE 2 & 0.75 & 0.56 & & & \\
\hline & PE 3 & 0.91 & 0.83 & & & \\
\hline & PE 4 & 0.90 & 0.81 & & & \\
\hline \multirow[t]{4}{*}{ Communication } & COM 1 & 0.85 & 0.72 & 0.84 & 0.87 & 0.68 \\
\hline & COM 2 & 0.89 & 0.79 & & & \\
\hline & COM 3 & 0.83 & 0.69 & & & \\
\hline & COM 4 & 0.72 & 0.52 & & & \\
\hline
\end{tabular}




\begin{tabular}{lcccccc}
\hline Collaboration & COL 1 & 0.73 & 0.53 & 0.80 & 0.90 & 0.62 \\
& COL 2 & 0.80 & 0.64 & & & \\
& COL 3 & 0.84 & 0.71 & & & \\
Resource Sharing & COL 4 & 0.76 & 0.58 & & 0.63 \\
& ROS 1 & 0.84 & 0.71 & 0.84 & & \\
& ROS 2 & 0.86 & 0.74 & & & \\
Behavior Intention & ROS 3 & 0.78 & 0.61 & & \\
& ROS 4 & 0.71 & 0.50 & & \\
& BOI 1 & 0.79 & 0.62 & 0.88 & & \\
& BOI 2 & 0.86 & 0.74 & & & \\
& BOI 3 & 0.89 & 0.79 & & & \\
& BOI 4 & 0.88 & 0.77 & & & \\
\hline
\end{tabular}

Discriminant validity: Discriminant validity estimates the extent to which a concept and its indicators differ from another concept and its indicators (Bagozzi et al., 1991). To test the discriminant validity, Fornell and Larcker's criteria were applied. According to Fornell and Larcker (1981), the correlations between items in any two constructs should be lower than the square root of the average variance shared by items within a construct. It has shown in the diagonal of Table 3.

Table 3: Mean, standard deviation, inter items correlation and discriminant validity

\begin{tabular}{ccccccccc}
\hline Construct & Mean & Std. Dev & PU & PE & COM & COL & ROS & BOI \\
\hline PU & 2.43 & 0.74 & $\mathbf{0 . 7 4}$ & & & & & \\
PE & 2.17 & 0.83 & 0.43 & $\mathbf{0 . 8 3}$ & & & & \\
COM & 2.06 & 0.79 & 0.38 & 0.70 & $\mathbf{0 . 8 3}$ & & & \\
COL & 2.24 & 0.68 & 0.31 & 0.60 & 0.59 & $\mathbf{0 . 7 9}$ & & \\
ROS & 2.56 & 0.71 & 0.18 & 0.40 & 0.40 & 0.46 & $\mathbf{0 . 8 0}$ & \\
BI & 2.34 & 0.74 & 0.31 & 0.49 & 0.52 & 0.57 & 0.54 & $\mathbf{0 . 8 5}$ \\
\hline
\end{tabular}

(PE $=$ Perceived Ease of Use, $P U=$ Perceived Usefulness, $C O M=$ Communication, $C O L=$ Collaborating Learning, $R O S=$ Resource Sharing, BOI= Behavior Intention)

In Table 3, Mean, Std. Dev, inter-item correlation and discriminant validity are presented. The diagonal value is the value of the square root of Average Variance Explained (AVE). Since all the diagonal values are higher than the inter items correlation, the discriminate validity is established.

Common method biases: To examine the common method bias issue, Herman's single factor test has been performed in which the variance explained by an un-rotated single factor is $30.54 \%$ which is less than the suggested threshold of 50\% (Podsakoff et al., 2003). Similarly, since the data set does not correlate more than 0.70, there are no common method biases (Baggozzi et al., 1991). Therefore, this research does not have common method biases.

Structural Model (Path Analysis): In the structural model, the paper establishes links between constructs through a set of paths, which usually reflects the hypotheses. The relationships between constructs can capture direct, indirect (mediated), and interaction (moderated) effects (Ringle et al., 2020). The results showed that the VIFs values are less than 3 . It indicates no issue of multi-collinearity in the data (Hew \& Kadir, 2016). Hypotheses of the Direct Effect have been estimated by Hypothesis $1,2 \mathrm{a}$, and $2 \mathrm{~b}$. 
Table 4: Direct effect of hypotheses testing

\begin{tabular}{lccccc}
\hline \multicolumn{1}{c}{ Constructs } & $\begin{array}{c}\text { Path } \\
\text { Coefficient }\end{array}$ & $\begin{array}{c}\text { Standard } \\
\text { Deviation }\end{array}$ & Standard Error & T-Value & $\begin{array}{c}\text { Significant } \\
\text { Level }\end{array}$ \\
\hline PE -> BOI & 0.576 & 0.0765 & 0.0765 & 6.480 & Significant \\
PU -> BOI & 0.373 & 0.0742 & 0.0742 & 5.100 & Significant \\
PE -> PU & 0.532 & 0.0845 & 0.0845 & 6.300 & Significant \\
\hline
\end{tabular}

(PU=Perceived Usefulness, $P E=$ Perceived Ease of Use, BOI= Behavior Intention)

The structural model shows the relationships (paths) between the constructs. First, H1 examines whether PE is positively related to BOI. The results showed that PE has significant impact (direct effect) on BOI $(\beta=0.576, t=6.48, p<0.001)$. Hence, H1 was supported. It implies that perceived ease of use has a significant influence on the behavioral intention. Second, H2 examines whether PU is positively related to BOI. The results showed that PU has significant impact (direct effect) on BOI $(\beta=0.373, t=5.10, p<0.001)$. Hence, $\mathrm{H} 2$ was supported. It implies that perceived usefulness has a significant influence on the behavioral intention of social media adoption. Finally, $\mathrm{H} 3$ examines whether PE is positively related to PU. The results showed that PE has significant impact (direct effect) on PU $(\beta=0.532, t=6.30, p<0.001)$. Hence, H3 was supported. It implies that perceived ease of use has a significant influence on perceived usefulness.

Mediated Effects: The mediated hypotheses have been estimated by hypotheses 3a, 3b, 4a, 4b, 5a, and $5 \mathrm{~b}$ respectively. The mediation analysis was estimated using the bootstrapping method with biascorrected confidence estimates (Preacher \& Hayes, 2008). The total effects are a total of direct effects and indirect effects (i.e. TE $=\mathrm{DE}+\mathrm{IE}$ ). In the present study, a 95\% confidence interval of the indirect effect was obtained with 5000 bootstraps resamples (Preacher \& Hayes, 2008). To further confirm the extent of mediation, the researcher also calculated variance accounted for (VAF) which refers to the ratio of indirect effect to total effect (Nitzl et al., 2016).

Table 5: Mediated effect of hypotheses testing

\begin{tabular}{cccccc}
\hline Construct & $\begin{array}{c}\text { Path } \\
\text { Coefficient }\end{array}$ & $\begin{array}{c}\text { Standard } \\
\text { Deviation }\end{array}$ & $\begin{array}{c}\text { Standard } \\
\text { Error }\end{array}$ & T-Value & $\begin{array}{c}\text { Significant } \\
\text { Level }\end{array}$ \\
\hline COL -> BOI & 0.576 & 0.58 & 0.083 & 6.70 & Significant \\
COL -> PU & 0.373 & 0.40 & 0.084 & 4.45 & Significant \\
PU -> BOI & 0.184 & 0.19 & 0.085 & 2.15 & Significant \\
COL -> BOI & 0.577 & 0.084 & 0.083 & 6.90 & Significant \\
COL -> PE & 0.606 & 0.077 & 0.074 & 7.90 & Significant \\
PE -> BOI & 0.227 & 0.093 & 0.093 & 2.45 & Significant \\
COM -> BOI & 0.530 & 0.085 & 0.085 & 6.237 & Significant \\
COM -> PU & 0.477 & 0.079 & 0.079 & 5.992 & Significant \\
PU -> BOI & 0.158 & 0.085 & 0.085 & 1.850 & Not Significant \\
COM -> BOI & 0.530 & 0.086 & 0.086 & 6.16 & Significant \\
COM-> PE & 0.719 & 0.061 & 0.062 & 11.69 & Significant \\
PE -> BOI & 0.267 & 0.120 & 0.120 & 1.966 & Significant \\
POE -> BOI & 0.491 & 0.080 & 0.079 & 6.161 & Significant \\
POE-> ROS & 0.421 & 0.081 & 0.081 & 5.188 & Significant \\
ROS -> BOI & 0.411 & 0.093 & 0.093 & 4.417 & Significant \\
\hline
\end{tabular}


In the hypothesis 3a, the analysis was examined [Total effects $(0.645)=$ Direct Effects $(0.577)+$ Indirect Effects (0.645). Variance Accounted for (VAF) is used Indirect Effect (0.0687)/Total Effect $(0.645)=0.106$. The VAF value of $10.6 \%$ confirms no mediation as per the criterion suggested by Hair et al. (2017). It implies there is no mediation but both direct effect and indirect effect are significant. In the hypothesis $3 b$, the analysis was examined [Total effects $(0.715)=$ Direct Effects $(0.577)+$ Indirect Effects (0.138). Variance Accounted for (VAF) is used Indirect Effect (0.138)/Total Effect $(0.715)=$ 0.193 . The VAF value of $19.3 \%$ confirms no mediation as per the criterion suggested by Hair et al. (2017). It implies there is no mediation but both direct effect and indirect effect are significant.

In the hypothesis $4 \mathrm{a}$, the analysis examined that [Total effects $(0.605)=$ Direct Effects $(0.53)+$ Indirect Effects (0.075). Variance Accounted for (VAF) is used Indirect Effect $(0.075) /$ Total Effect $(0.53)=$ 0.142 . The value of VAF is $14.2 \%$ which is less than $20 \%$. The VAF value of $14.2 \%$ confirms no mediation as per the criterion suggested by Hair et al. (2017). It implies there is no mediation but both direct effect and indirect effect are significant. In the hypothesis $4 \mathrm{~b}$, the analysis examined [Total effects $(0.769)=$ Direct Effects (0.577) + Indirect Effects (0.192). Variance Accounted for (VAF) is used Indirect Effect $(0.192) /$ Total Effect $(0.769)=0.25$. The value of VAF is $25 \%$ which is more than $20 \%$. The VAF value of 25\% confirms partial mediation as per the criterion suggested by Hair et al. (2017). It implies there are partial mediation and both direct effect and indirect effect are significant. However, the presence of the mediating effect of perceived ease of use is less strong than the direct effect.

In hypothesis $5 \mathrm{a}$, there is a direct effect from resource sharing \& behavioral intention, perceived usefulness, and behavioral intention have been found significant. However, there is no relationship between resource sharing and behavioral intention has no significant relationship. Since there is no relationship between resource sharing and perceived usefulness, the mediation test will not be tested. In the hypothesis $5 b$, the analysis examined [Total effects $(0.664)=$ Direct Effects $(0.491)+$ Indirect Effects (0.173). Variance Accounted for (VAF) is used Indirect Effect (0.173)/Total Effect $(0.491)=$ 0.35 . The value of VAF is $35.23 \%$ which is more than $20 \%$. The VAF value of $35.23 \%$ confirms partial mediation as per the criterion suggested by Hair et al. (2017). It implies there are partial mediation and both direct effect and indirect effect are significant. However, the presence of the mediating effect of perceived ease of use is less strong than the direct effect.

\section{Discussion}

The objective of the paper was to examine the social media adoption by undergraduate students of Business Schools in Kathmandu Valley. To achieve the research objective, the researcher conceptualized the research model based on Arshad and Akram (2018) which was postulated theoretical grounding of the technology acceptance model and social constructivist paradigm. Consistent with previous research, this research confirms significant support for the academic usage of social media (Arshad \& Akram, 2018; Berger, 2017; Sobaih et al., 2016).

First, this research found that perceived ease of use has a significant effect on behavior intention of social media adoption. The result is consistent with the findings of previous researchers (Van Raaij \& Schepers, 2008; Mazman \& Usluel, 2010). Second, this research found that perceived usefulness has a significant effect on behavior intention of social media adoption. It is consistent with the findings of previous researchers (Davis, 1989; Pokhrel, Adhikari \& Mishra, 2020). Third, this research found that perceived ease of use has a significant influence on perceived usefulness. It is consistent with the findings of previous researchers (Davis, 1989; Pokhrel et al., 2020). Therefore, this research further substantiates the technology acceptance model. It implies that students of Nepali business schools are intended to use social media for educational purposes if the social media sites are easy to use, useful for educational purposes. Moreover, collaboration, communication, and resource sharing have a significant impact on social media adoption in the academic community (Arshad \& Akram, 
2018, Mazman \& Usluel, 2010; Sánchez et al., 2014). On the other hand, this research found partial mediation of perceived ease of use on resource sharing and communication on the intention of social media adoption. It is consistent with the findings of (e.g. Arshad \& Akram, 2018; Berger, 2017; Sobaih et al., 2016). It is consistent with the constructivism theory (Vygotsky, 1978). It shows that resource sharing and communication influence the intention of social media adoption along with perceived ease of use. It implies that undergraduate level students are intended to use social media if it is easy to use the platform, resources are shared with communication in a meaningful way.

\section{Conclusion}

With the exponential growth and adaptability of social media among the young generation, this research postulated the research question of whether social media can be used for communication, collaboration, and resource sharing among business schools students in Kathmandu Valley. The intention of the study is to examine social media adoption among undergraduate-level students. The result showed that perceived ease of use, perceived usefulness, collaboration, resource sharing and communication have a significant influence on intention of social media adoption. Moreover, this research found that communication and resource sharing has significant effect on intention of social media adoption along with perceived ease of use. This is aligned with the theoretical foundations of the technology acceptance model and constructivist theory. Thus, business schools can apply social media platforms to collaborate, communication, and share resource between students, and faculties where basic modern collaboration and communication are not available (Curtis et al., 2010; Sobaih et al., 2016). The paper concludes that undergraduate level students of business schools could intent to social media when they find the social media useful, easy to use, collaborative, communication, and resource sharing among students. Moreover, students could intend to use social media when they perceived ease of social media use over communication, resource sharing for educational purposes. The conclusion could provide information for business schools in creating an atmosphere of collaboration, communication, and resource sharing to increase engagement in social media.

The findings of the paper could provide several areas for further research. The study was undertaken in the academic community so the findings can be utilized to formulate educational policy to increase the engagement of students in teaching and learning. Moreover, higher education institutions could build social media adoption as a competitive advantage. On the other hand, the researcher can incorporate personality, social influence and perceived enjoyment could be influencing social media adoption intention influenced in higher education through a unified theory of technology acceptance model. This research provides insight into social media adoption in the business school of management, however, the findings of the research should be carefully interpreted to draw inferences from the result. The paper has several avenues for future research. First, the self-reported bias were not eliminated because the study captured variables of the paper with self-reported measures. Second, since the respondents of the paper were undergraduate students, the paper could seriously impact the generalizability of the research outcome. So sample size could be drawn by applying probability sampling with increasing the sample size result in representative and generalizable. Third, cross-sectional correlation research designs have been utilized so that longitudinal study and experimental research designs could capture the variables in meaningful ways. Fourth, the quantitative research method has been used to measure the COL, COM, ROS, PU, PE, and BOI among undergraduate students in which all variables are subjective, and so using quantitative methods may not reflect the perception or view of the employees completely. Finally, qualitative or mixed-method could capture the phenomena of interest more accurately.

\section{Conflict of Interest}

There is no conflict of interest while preparing this article. 


\section{References}

Al-Ghaith, W. (2015). Applying the technology acceptance model to understand social networking sites (SNS) usage: Impact of perceived social capital. International Journal of Computer Science and Information Technology, 7(4), 105-117.

Arshad, M. \& Akram, M. (2018). Social media adoption by the academic community: theoretical insights and empirical evidence from developing countries. The International Review of Research in Open and Distributed Learning, 19(3), Athabasca University Press. Retrieved August 14, 2021 from https://www. learntechlib.org/p/184548/

Bagozzi, R. P., Yi, Y., \& Phillips, L. W. (1991). Assessing construct validity in organizational research. Administrative Science Quarterly, 421-458.

Berger, P. (2017). Beyond plain acceptance or sheer resistance: A typology of university instructors' attitudes to students' media use in class. Teaching and Teacher Education, 67, 410-417.

Bock, G.W., Zmud, R., Kim, Y.G., \& Lee, J.-N. (2005). Behavioral intention formation in knowledge sharing: Examining the roles of extrinsic motivators, social-psychological forces, and organizational climate. Management Information Systems Quarterly, 29(1).

Boonsiritomachai, W., \& Pitchayadejanant, K. (2019). Determinants affecting mobile banking adoption by generation $\mathrm{Y}$ based on the unified theory of acceptance and use of technology model modified by the technology acceptance model concept. Kasetsart Journal of Social Sciences, 40(2), 349-358.

Christofides, E., Muise, A., \& Desmarais, S. (2009). Information disclosure and control on Facebook: Are they two sides of the same coin or two different processes? Cyber Psychology \& Behavior, 12(3), 341-345.

Davis, F. D. (1989). Perceived Usefulness, perceived ease of use, and user acceptance of information technology. MIS Quarterly, 13(3), 319-340.

Domizi, D. P. (2013). Microblogging to foster connections and community in a weekly graduate seminar course. Tech Trends, 57(1), 43-51.

Dumpit, D. Z., \& Fernandez, C. J. (2017). Analysis of the use of social media in Higher Education Institutions (HEIs) using the Technology Acceptance Model. International Journal of Educational Technology in Higher Education, 14(1), 1-16.

Forkosh-Baruch, A., \& Hershkovitz, A. (2012). A case study of Israeli higher-education institutes sharing scholarly information with the community via social networks. The Internet and Higher Education, 15(1), 58-68.

Fornell, C., \& Larcker, D. F. (1981). Structural equation models with unobservable variables and measurement error: Algebra and Statistics.

Hair, J. F., Hult, G. T. M., Ringle, C. M. and Sarstedt, M., (2016) (2nd ed.). A Primer on Partial Least Squares Structural Equation Modeling (PLS-SEM).Thousand Oaks, CA: Sage.

Hayes, T. J., Ruschman, D., \& Walker, M. M. (2009). Social networking as an admission tool: A case study in success. Journal of Marketing for Higher Education, 19(2), 109-124.

InternetLiveStats. (2020). Internet usage-social media statistics. Retrieved from http://www.internetlivestats.com/

Johnson, D. W., \& Johnson, R. T. (1999). Making cooperative learning work. Theory into Practice, 38(2), 67-73. Retrieved from https://doi.org/10.1080/00405849909543834

Kaplan, A. M., \& Haenlein, M. (2010). Users of the world, unite! The challenges and opportunities of Social Media. Business Horizons, 53(1), 59-68.

Kietzmann, J. H., Hermkens, K., McCarthy, I. P., \& Silvestre, B. S. (2011). Social media? Get serious! Understanding the functional building blocks of social media. Business Horizons, 54(3), 241-251. Retrieved from https:// doi.org/10.1016/j.bushor.2011.01.005

Lederer, K. (2012). Pros and cons of social media in the classroom. Campus Technology, 25(5), 1-2.

Lester, J. \& Perini, M. (2010). Potential of social networking sites for distance education student engagement. New Direction for Community Colleges, 2010(50), 67-77.

Lowry, G. (2002). Modelling user acceptance of building management systems. Automation in Construction, 11(6), 695-705. 
Lu, J., Yao, J. E., \& Yu, C.-S. (2005). Personal innovativeness, social influences and adoption of wireless Internet services via mobile technology. The Journal of Strategic Information Systems, 14(3), 245-268. Retrieved from https://doi.org/10.1016/j.jsis.2005.07.003

MacKinnon, D. P., Lockwood, C. M. and Williams, J., (2004). Confidence Limits for the Indirect Effect: Distribution of the Product and Resampling Methods. Multivariate Behavioral Research, 39(1), 99-128.

Maloney, E. (2007). What Web 2.0 can teach us about learning? Chronicle of Higher Education, 53(18), B26.

Marangunić, N., \& Granić, A. (2015). Technology acceptance model: a literature review from 1986 to 2013. Universal Access in the Information Society, 14(1), 81-95.

Mazer, J. P., Murphy, R. E., \& Simonds, C. J. (2007). I'll see you on "Facebook": The effects of computer-mediated teacher self-disclosure on student motivation, affective learning, and classroom climate. Communication education, 56(1), 1-17.

Mazman, S. G., \&Usluel, Y. K. (2010). Modeling educational usage of Facebook. Computers \& Education, 55(2), 444-453.

Nitzl, C., Roldan, J.L. and Cepeda, G. (2016). Mediation analysis in partial least squares path modeling: Helping researchers discuss more sophisticated models. Industrial Management \& Data Systems. 116(9), 18491864.

Nunnally, J.C., \& Bernstein, I.H. (1994). Psychometric Theory (3rd ed.). New York: McGraw-Hill.

Pallant, J. (2020). SPSS Survival Manual: A step by step guide to data analysis using IBM SPSS. Routledge.

Pandey, S., \&Yadama, G. N. (1992). Community development programs in Nepal: a test of diffusion of innovation theory. Social Service Review, 66(4), 582-597.

Podsakoff, P. M., MacKenzie, S. B., Lee, J.-Y., \& Podsakoff, N. P. (2003). Common method biases in behavioral research: a critical review of the literature and recommended remedies. The Journal of Applied Psychology, 88(5), 879-903.

Pokhrel, L., Adhikari, D., \& Mishra, A. K. (2020). Adoption of Mobile Banking Among Users in Kathmandu Valley: Lens of Technological Acceptance Model. NOLEGEIN Journal of Management Information Systems, 3(2), 1-7.

Preacher, K.J., Hayes, A.F. (2008). Asymptotic and resampling strategies for assessing and comparing indirect effects in multiple mediator models. Behavior Research Methods 40(3), 879-891. Retrieved from https:// doi.org/10.3758/BRM.40.3.879

Rauniar, R., Rawski, G., Yang, J. and Johnson, B. (2014). Technology acceptance model (TAM) and social media usage: an empirical study on Facebook. Journal of Enterprise Information Management, 27(1), 6-30. https://doi.org/10.1108/JEIM-04-2012-0011

Ringle, C. M., Wende, S., \& Becker, J. M. (2015). Smart PLS 3 [computer software]. Smart PLS GmbH.

Ringle, C., Da Silva, D., \& Bido, D. (2015). Structural equation modeling with the SmartPLS. Bido, D., da Silva, D., \& Ringle, C. (2014). Structural Equation Modeling with the Smartpls. Brazilian Journal of Marketing, 13(2).

Ross, C., Orr, E. S., Sisic, M., Arseneault, J. M., Simmering, M. G., \& Orr, R. R. (2009). Personality and motivations associated with Facebook use. Computers in Human Behavior, 25(2), 578-586. Retrieved from https://doi. org/10.1016/j.chb.2008.12.024

Sánchez, R. A., Cortijo, V., \&Javed, U. (2014). Students' perceptions of Facebook for academic purposes. Computers \& Education, 70(1), 138-149.

Sandvig, J. C. (2016). The role of social media in college recruiting. International Journal of Web Based Communities, 12(1), 23-34.

So, H. J., \& Brush, T. A. (2008). Student perceptions of collaborative learning, social presence and satisfaction in a blended learning environment: Relationships and critical factors. Computers \& Education, 51(1), 318-336.

Sobaih, A. E. E., Moustafa, M. A., Ghandforoush, P., \& Khan, M. (2016). To use or not to use? Social media in higher education in developing countries. Computers in Human Behavior, 58, 296-305. Retrieved from https://doi.org/10.1016/j.chb.2016.01.002 
Van Raaij, E. M., \& Schepers, J. J. (2008). The acceptance and use of a virtual learning environment in China. Computers \& Education, 50(3), 838-852.

Venkatesh, V., \& Davis, F. D. (2000). A theoretical extension of the technology acceptance model: Four longitudinal field studies. Management Science, 46(2), 186-204. Retrieved from https://doi.org/10.1287/ mnsc.46.2.186.11926

Vygotsky, L. S. (1978). Mind in Society: The development of higher psychological processes. Cambridge, MA: Harvard University Press.

Yadegaridehkordi, E., Noor, N. F. B. M., Ayub, M. N. B., Affal, H. B., \& Hussin, N. B. (2019). Affective computing in education: A systematic review and future research. Computers \& Education, 142, 103649. Retrieved from https://doi.org/10.1016/j.compedu.2019.103649

\section{Appendix: Questionnaires or Instruments}

Usefulness adapted from Davis (1989) and Venkatesh and Davis (2000)

- Using Social Media enables me to accomplish tasks more quickly.

- I find Social Media useful in my studies/research.

- If I use Social Media, it will increase my chances of getting a better position.

- Using Social Media increases my productivity.

Communication adapted from Ozkan and Koseler (2009)

- I think communicating with the instructor/colleagues via Social Media is important and valuable.

- Social Media makes the communication easier with instructor/colleagues and other classmates for me.

- The instructor/colleagues are good at communicating with each other via Social Media.

- The instructor/colleague encourages us/me to interact with other students/colleagues by using Social Media interactive tools.

Ease of Use adapted from Davis (1989) and Venkatesh and Davis (2000)

- It is easy for me to become skillful at using Social Media.

- My interaction with Social Media is clear and understandable.

- Learning to operate Social Media is easy for me.

- I find Social Media easy to use.

Collaborative learning adapted from So and Brush (2008)

- I can develop new skills and knowledge from other members of my group.

- I actively exchange my ideas with group members.

- Collaborative learning by using Social Media is effective.

- Overall, I am satisfied with my collaborative learning experience by using Social Media.

Social media adoption Intention adapted from Bock et al. (2005)

- I predict that I would adopt Social Media for knowledge sharing.

- I intend to adopt Social Media for knowledge sharing.

- I will continue using Social Media for knowledge sharing.

- I plan to continue using Social Media for knowledge sharing.

Resource sharing adapted from Bock et al. (2005)

- Sharing of my knowledge with other members of Social Media is always beneficial.

- Sharing of my knowledge with other members of Social Media is always good.

- Sharing of my knowledge with other members of Social Media is always a wise move.

- Sharing of my knowledge with other members of Social Media is always an enjoyable experience.

(Adopted from Arshad \& Akram, 2018) 